\title{
Tradução
}

\section{O nominalismo da relação como princípio antimetafísico ${ }^{1}$}

\section{Diogo Sardinha ${ }^{2}$}

\begin{abstract}
Apesar de todas as diferenças e divergências que se pode assinalar entre as obras de Marx e de Foucault, ninguém ignora que podem permanecer marcadas por uma necessidade comum de abandono do terreno da filosofia. É o que, aliás, anuncia o primeiro, quando pretende ter acertado suas contas com sua antiga consciência filosófica ${ }^{3}$ e faz o segundo ao recordar que aprendeu mais com Cuvier, Bopp e Ricardo do que com Kant
\end{abstract}

1 Tradução do francês por Gustavo Chataignier (PUC-Rio) a partir do original SARDINHA, Diogo. "Le nominalisme de la relation comme principe antimétaphysique". In : LAVAL, C., PALTRINIERI, L. E TAYLAN, F. (org.). Marx \& Foucault : lectures, usages, confrontations. Paris: La Découverte/ Recherches, 2015, pp. 244-257.

2 Professor do Departamento de Filosofia da Universidade de Lisboa, membro integrado do Centro de Filosofia das Ciências da Universidade de Lisboa e o primeiro presidente estrangeiro do Colégio Internacional de Filosofia em Paris. Texto redigido com o apoio financeiro da Fundação para a Ciência e Tecnologia de Portugal e do Fundo Social Europeu.

3 Karl MARX, « Vorwort », << Zur Kritik der Politischen Ökonomie », in Karl MARX et Friedrich ENGELS, Werke, Dietz Verlag, Berlin, 1971, volume xnl, p. 10. Voir Karl MARX, « Préface » [Prefácio], in Contribution à la critique de 1 'économie politique [Contribuição à crítica da economia política], Éditions sociales, Paris, 1972. 
ou Hegel ${ }^{4}$. Saber em direção a qual terreno cada uma dessas obras se desloca, se chegam ou não a romper completamente com a filosofia, ou bem se, em se chegando parcialmente, permanecem ainda obras filosóficas, são interrogações que não podem ser formuladas senão ao se levar a sério suas vontades de ruptura com a filosofia. Isso leva a dois apontamentos suscetíveis de servir de ponto inicial à análise. Primeiramente, saber se, em absoluto, Marx e Foucault são ou não filósofos é uma questão mal colocada. Por esse viés, não se pode senão visar a uma resposta inteiramente positiva ou negativa. Com efeito, seria quase banal dizer que um e outro, notadamente formados pela filosofia, nunca cessam inteiramente de recorrer a seus esquemas de pensamento, apenas para melhor deles se distinguir, e por aí mesmo são suscetíveis de serem lidos filosoficamente. Ora, o importante não está aí, mas, antes, no segundo apontamento que consiste em inquirir as razões de seu desejo comum de se afastar da filosofia - desejo este que se exprime com força tanto em seus objetos de estudo quanto nos métodos mobilizados para os tratar. Lançaremos aqui a hipótese de que uma dessas razões, talvez a principal, toca na centralidade das essências na tradição filosófica. Tal centralidade tem duas vertentes que apenas se opõem em aparência: em uma, a filosofia é antes de mais nada busca por essências; em outra, as essências não são senão o resultado de elaborações epistemológicas ou cognitivas por meio das quais o pensamento faz abstração das características comuns dos entes singulares, até alcançar a universalidade. Essas duas posições aqui sumariamente descritas são respectivamente designadas como realista e nominalista. Assim, na medida em que ambas são intimamente ligadas ao problema das essências, podem portanto ser legitimamente olhadas como o verso e o reverso da mesma medalha filosófica. Se, desse ponto de vista, Marx e Foucault não são nem realistas e tampouco nominalistas, é porque lhes é preciso romper com as duas tradições a fim de poder cambiar de terreno.

Porém, essa afirmação põe um problema a ser necessariamente resolvido de modo preliminar. Notadamente o fato de

$4 \quad$ Michel FOUCAULT, Les Mots et les Choses [As palavras e as coisas], Gallimard, Paris, 1966, p. 318. 
que Foucault por vezes se reclama do nominalismo, e que Marx pôde ser olhado, por exemplo por Balibar, como um nominalista. Esse ponto merece portanto ser examinado de perto. Três interrogações podem ser formuladas: primeiramente, de onde vem exatamente a ideia segundo a qual o mal-estar experimentado por Marx e Foucault em relação à filosofia tenha ligação com a presença constante do problema das essências? Em segundo lugar, como um e outro se livram desse problema? Não seria justamente com essa finalidade que Foucault evoca o nominalismo? Em terceiro lugar, quais mecanismos poderiam evitar o retorno a um pensamento das essências, uma vez tendo sido evacuado? Eis as questões que nos servirão de fio condutor.

\section{A dissolução da essência humana}

O texto "Foucault et Marx. L'enjeu du nominalisme $»^{5}$, de Étienne Balibar, foi um dos primeiros na França a trazer à tona o benefício que representa, para os que vêm após ambos autores, o fato de dispor de ambos corpus ${ }^{6}$. Em seu ponto de vista, uma das razões pelas quais Foucault é útil àqueles que, como ele, se esforçam em pensar com Marx para além de Marx, concerne a relação que ele estabelece com a filosofia. Foucault, escreve Balibar, fez um «'salto' da filosofia na não-filosofia, que subitamente descobre um outro rosto das questões filosóficas (as da verdade, do poder e da prática, as do tempo e do sujeito). Dito isso, se nosso interesse é o de determinar em quê nosso horizonte filosófico é irreversivelmente pós-marxista (no duplo sentido da expressão), a leitura de Foucault constitui um viés privilegiado"". Para Étienne Balibar, nesse texto de 1989,

Nt: "Foucault e Marx. A questão do nominalismo", sem tradução em português.

6 A despeito dos seus méritos, o destino desse escrito ficou calado por um período, por razões que Fathi Triki soube dar voz. Após a transcrição do debate, Triki reproduz "uma longa citação de Foucault para precisar as relações de Foucault com o marxismo, relações estas que são de distanciamento, e não de combate". Ver Étienne BALIBAR, « Foucault et Marx. L'enjeu du nominalisme » in Michel Foucault philosophe. Rencontre internationale [Michel Foucault filósofo. Encontro internacional], Paris, 9, 10, 11 janvier 1988, Seuil, Paris, 1989, p. 54-76 et p. 76.

7

Ibid., p. 72. 
a não-filosofia em direção da qual se orienta Foucault aparece menos como uma filosofia negativa - que sempre permanece uma filosofia -, do que uma reflexão. Esta, ao sair da filosofia, quer dizer, ao lhe dispensar já que não tem mais serventia e ao retomar por vias alternativas problemas por ela moldados, desemboca em outras modalidades de pesquisa. Essas modalidades de pesquisa podem ser, por exemplo, históricas, quer seja sob a forma da arqueologia, quer seja da genealogia, e assim projetar uma luz inesperada em temas e conceitos classicamente filosóficos. E efetivamente, para Foucault, não é pela via do comentário que se aproxima verdadeiramente dos problemas, mas ao se levar em conta materiais históricos ${ }^{8}$. De toda evidência, essa posição o aproxima de Marx, cujos estudos tanto históricos quanto proto-sociológicos, quase sempre caraterizados por uma sede de "concretude", marcam seus artigos de jornal sobre as condições de vida e de trabalho dos desvalidos, tanto quanto $O$ Capital, notadamente pelo lugar que confere às relações elaboradas pelos inspetores de trabalho no interior das fábricas. Aqui como em outros lugares, lida-se com o que é experimentado como os limites da potência filosófica. Limites que Marx e Foucault procuraram romper, menos na esperança de aumentar o campo da filosofia (o que, talvez paradoxalmente, tenha sido um dos efeitos reais de suas empreitadas), do que na ideia dela sair ou se distinguir.

Sugerimos mais acima que uma das vantagens encontradas nessa saída do campo da filosofia, quiçá sua principal vantagem, consiste na possibilidade que oferece para que se pare de levar em consideração as essências. Sob esse ângulo, o recurso ao texto de Balibar, "Foucault e Marx. A questão do nominalismo", pode igualmente ser útil. Balibar retoma de Foucault o termo "nominalismo", para o confrontar à noção de "materialismo histórico". Dessa confrontação, ele retira um novo conceito, o "nominalismo histórico", do qual uma das virtudes consiste em "dissolver radicalmente as idealidades, como

$8 \quad$ Ver, por exemplo, Michel Foucault, « De l'archéologie à la dynastique » [Da arqueologia ao dinástico ], in Dits et écrits [Ditos e escritos] (19541988), Gallimard, Paris, 1994, tomo 1l, p. 406-407. 
'o sexo', 'a razão', 'o poder' ou 'a contradição'”'. Efetivamente, a prática de dissolução das idealidades convém a Foucault que, em seu vocabulário, as chama de "universais". No entanto, nada garante a priori que seja apropriada para também descrever o método marxiano. É todavia a hipótese de "Marx e Foucault. A questão do nominalismo", que almeja que tal preocupação lhes seja comum. Seria talvez mais radicalmente buscada por Marx do que por Foucault, o primeiro dissolvendo elementos que o outro teria ainda conservado como entidades, sem chegar a olhá-los como relações. Mais exatamente, o texto sugere que Foucault pensa os corpos enquanto corpos, quer dizer, de algum modo como substâncias, ao passo que Marx os pensa "em termos de relações", assim dissolvendo sua espessura substancial. É a razão pela qual Balibar sugere que o "nominalismo consequente - o menos metafísico entre ambos"10 é o de Marx. Em suma, o pensamento das relações que desfaz idealidades seria comum aos dois autores, e seria um critério que permite se postular (sem no entanto definir de maneira sumária) que um a pratica de maneira melhor acabada do que o outro.

Isso não basta para se explicar em quê suas rupturas com a filosofia seriam associadas ao abandono das essências. Para tanto, "A filosofia de Marx", de Balibar, se assevera mais útil11. Ora, as passagens do livro que concernem esse ponto se ligam à interpretação da sexta tese sobre Feuerbach proposta pelo autor, e mais, rigorosamente, suas primeiras linhas. É portanto necessário se recordar o que enunciam: "Feuerbach resolve a essência religiosa na essência humana. Mas a essência humana não é uma abstração inerente ao indivíduo singular. Em sua realidade

9 Étienne BALIBAR, $<<$ Foucault et Marx. L'enjeu du nominalisme » in Michel Foucault philosophe. Rencontre internationale. op. cit., p. 74.

10 lbid., p. 75. Para um outro estudo das ligações entre Marx, Foucault e o nominalismo, ver a tese de doutorado de Monica STWAL, $<<$ M. Foucault entre a crítica e o nominalismo », Universidade de São Paulo, 2013. Disponível em: <http://www.teses.usp.br/teses/disponiveis/8/8133/tde24062013-132203/pt-br.php>.

11 Étienne BALIBAR, La Philosophie de Marx, La Découverte, Paris, 2014. 
efetiva, ela é o conjunto de relações sociais"12. Se se interpreta essas linhas à luz das análises foucaultianas, uma coisa se torna clara: quando Marx faz referência à essência humana, não o faz, por assim dizer, senão em aparência, e de maneira crítica; em uma palavra, do modo a dissolvê-la no "conjunto das relações sociais". Dito de outra maneira, afirmar a "essência humana das relações sociais" não redunda em fornecer uma definição concreta da essência; isso consiste, antes, em deslocar o problema em um outro terreno que não o da essência no singular (ou de algo que seria captado enquanto essência), para pô-lo no terreno da pluralidade das relações entre os seres humanos. Seres humanos que não podem eles mesmos serem definidos de maneira estável, pois em seus modos de ser (e não mais, justamente, pela essência), se tornam os polos das relações sociais das quais dependem. Em outros termos, essas relações precedem tudo aquilo que poderia ser captado como essência humana, posto que os seres humanos singulares só se determinam nas e pelas relações sociais. Nessa nova perspectiva, o "indivíduo singular" evocado na sexta tese é substituído por seres humanos plurais, dentre os quais há, de um lado, as relações sociais; e que, por outro, dependem dessas mesmas relações. As entidades múltiplas que são os humanos dependem então de relações múltiplas e cambiantes, que são o social. Em definitivo, declarar que a essência humana é o conjunto das relações sociais implica em fazer valer a razão que impede de sustentar um discurso fundado sobre o sujeito da essência humana.

Uma outra interpretação permite igualmente exprimir e compreender, a partir da sexta tese, a ideia da impossibilidade da essência humana: na verdade, o que, eventualmente, aparece como a essência humana não é nada mais, nada menos, do que a cristalização, em um dado momento, do estado no qual se encontram as relações sociais. Eis porque, no lugar de negar toda forma de existência à "essência humana", seria sem dúvida mais justo afirmar sua existência em um certo sentido, ou seja, enquanto é produzida, praticamente e teoricamente, como função de uma situação de complexidade social. Sem dú-

$12 \quad$ Citado por Étienne BALIBAR, La Philosophie de Marx, op. cit., p. 51, segundo a tradução de Georges Labica. 
vida, seria preciso mesmo se chegar a afirmar que a essência humana não é, e que no entanto há essência humana, como produto ou efeito real que, por sua vez, se torna causa de outros efeitos. Como se compreenderia, caso contrário, todos os discursos e práticas visando a conformar seres humanos a sua pretensa essência? Isso não se dá sem que nos lembremos de algumas retóricas educativas, de controle, até de emancipação. É também necessário admitir que existe algo como "essência humana", com as aspas se prestando a indicar nesse contexto que o sintagma designa um produto e não uma natureza.

Diversas frases do complemento de 2014 à "Filosofia de Marx", intitulado "Antropologia filosófica ou ontologia da relação? O que fazer da VI tese sobre Feuerbach?", caminham nesse sentido. Eis aqui duas delas: o « conceito de Wesen (ser ou essência) não tem outro conteúdo senão uma atividade ou um processo, em outros termos, uma práxis"; e "o que visa a crítica marxiana não é somente uma representação (ainda) abstrata da essência humana, à qual se oporia uma concepção concreta da essência, mas é a noção mesmo de uma essência do homem que é uma 'abstração"' sas ideias que aproximam Marx e Foucault: de um lado, a insistência sobre o fato de que o "conteúdo" não é uma substância, mas uma prática e uma relação; e, de outro, a afirmação de que a substituição da representação abstrata da essência por uma concepção concreta dessa essência é ainda uma operação filosófica (e não não-filosófica, no sentido já mencionado), operação que portanto não muda o quadro. Em contraste com ela, Marx e Foucault convidam, cada um a sua maneira, a se sair da filosofia ao se apartar das essências, quer sejam ditas "abstratas" ou "concretas". É o que quer dizer a passagem na não-filosofia.

\section{Um novo nominalismo}

Após ter posto em evidência, a propósito de Marx e de Foucault, a ligação problemática entre essência e filosofia, de um lado, e, de outro, o gesto de se desvencilhar da filosofia para tentar se subtrair do império das essências, vejamos ago-

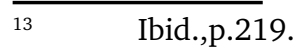


ra por qual mecanismo metodológico Foucault, e talvez Max, esperam evitar as armadilhas essencialistas. Parece que esse mecanismo é precisamente o nominalismo. Para provar essa hipótese, será oportuno recorrer a dois momentos nos quais Foucault reivindica um método nominalista: o primeiro foi extraído de "A vontade de saber", e o segundo de "O Nascimento da biopolítica". O conceito é de início explicitamente evocado no primeiro tomo de "História da sexualidade", onde se lê: "É preciso sem dúvida ser nominalista: o poder não é uma instituição, e não é uma estrutura, não é uma certa potência da qual alguns seriam dotados: é o nome que se dá uma situação estratégica complexe em uma sociedade dada"14. Essa afirmação, nos lembramos, se opõe notadamente à ideia de poder como propriedade. Não obstante, é necessário notar que o nominalismo, tal como aqui é apresentado, não corresponde à posição nominalista tradicional, cujo desejo era o de se ver, por detrás dos nomes, entidades singulares. Ao contrário, aqui ele indica um feixe de relações, graças ao qual a realidade do poder se dissolve, sua solidez se desfaz. Essa posição pode ser esclarecida por um outro exemplo tirado da mesma obra, cerca de quinze páginas após. Sobre o tema da sexualidade, "A vontade de saber" precisa que "é necessário não [o] conceber como um tipo de natureza dada que o poder tentaria de ver, ou como um domínio obscuro que o saber tentaria, pouco a pouco, desvelar. É o nome que se dá a um dispositivo histórico: não a realidade em cima da qual se exerceriam apropriações difíceis, mas uma grande rede de superfície onde a estimulação dos corpos, a intensificação dos prazeres, a incitação ao discurso, a formação dos conhecimentos, o reforço dos controles e das resistências, se encadeiam uns com os outros, segundo algumas grandes estratégias de saber e de poder"15. De toda evidência, a expressão que convém guardar é "o nome que se dá a": "sexualidade" é antes de tudo um nome, não uma "realidade", como escreveu. Não é isso o sinal que devemos sem dúvida, lá também, ser nominalistas? Aqui como em outras situações, uma unidade substancial é trocada por uma rede, por relações.

$14 \quad$ Michel FOUCAULT, Histoire de la sexualité. La volonté de savoir [História da sexualidade. A vontade de saber], Paris, Gallimard, 1976, p. 123. $15 \quad$ lbid., p. 139. 
Três anos mais tarde, em "O Nascimento da biopolítica", Foucault recorre de novo à mesma noção, o que permite esclarecer a significação que atribui ao termo. Eis o que diz o "Resumo do curso": "O que se deve entender por 'liberalismo'? Apoiei-me nas reflexões de Paul Veyne sobre os universais históricos e a necessidade de se testar um método nominalista em história"16. Assim como no que tange o poder e a sexualidade, essas frases indicam que o liberalismo não deve ser tomado com um "tipo de natureza dada", mas, antes de tudo, como um nome. A reivindicação do princípio nominalista é detalhada desde as primeiras páginas do curso. Ela é aí oposta ao princípio historicista. Este, diz Foucault, parte "dos universais para daí deduzir os fenômenos concretos" ou "dos universais como grade de inteligibilidade obrigatória para um certo número de práticas concretas"17, enquanto que seu desejo é o de "partir dessas práticas concretas e de algum modo passar pelos universais na grade dessas práticas ${ }^{18 ”}$. Em suma, tomar essas práticas como ponto de partida:

"A decisão, ao mesmo tempo teórica e metodológica, que consiste em dizer: suponhamos que os universais não existam, coloca nesse momento a questão à história e aos historiadores: como vocês podem escrever a história se não admitem a priori que algo como o Estado, a sociedade, o soberano, os sujeitos existem? (...) Suponhamos que a loucura não exista. Desde então, qual é, logo, a história que se pode fazer desses diferentes acontecimentos, de suas diferentes práticas que, aparentemente, se ordenam segundo esse algo suposto que é a loucura. É portanto exatamente o inverso do historicismo que gostaria aqui de estabelecer. Não, assim, interrogar os universais utilizando como método de crítica a história, mas partir da decisão da inexistência dos universais para se demandar qual história é possível de se fazer"19.

16 Michel FOUCAULT, $<<$ Résumé du cours » [Resumo do curso], in Naissance de la biopolitique. Cours au collège de France [Nascimento da biopolítica. Curso no Collège de France] (1978-1979), Paris, EHESS/Seuil/ Gallimard, 2004, p. 323.

Ibid., p. 6.

19

Ibid. 
Como se pode constatar, o historicismo aparece como o avatar, no seio da enquete histórica, do princípio realista que quer que a essência preceda os objetos a serem estudados princípio ao qual se opõe Foucault.

Um passo suplementar na contestação dos universais é dado em "Foucault", entrada de dicionário assinada pelo próprio sob o pseudônimo Maurice Florence, e redigida no início dos anos de 1980. Foucault desenvolve então a ideia de que uma crítica dos universais antropológicos permite a abordagem de parte importante de suas pesquisas conduzidas pela orientação nominalista, os "universais antropológicos" surgindo desde então como o termo pelo qual indica que seus trabalhos sobre a loucura, a delinquência ou a sexualidade se deixam compreender, no fundo e em seu conjunto, como vias para se tratar o problema do humano. O mesmo artigo explicita ainda o princípio que o autor se deu, o de um "ceticismo sistemático em relação a todos os universais antropológicos", significando que "tudo o que nos é proposto em nosso saber, como validade universal, quanto à natureza humana ou às categorias passíveis de aplicação no sujeito, demanda a ser provado e analisado"20. Acrescenta ainda a esses universais "aqueles de um humanismo que fariam valer os direitos, os privilégios, a natureza de um ser humano como verdade imediata e intemporal do sujeito". Isso leva a crer, caso tenhamos em mente a oposição entre nominalismo e historicismo, que a antropologia da natureza ou da essência, o humanismo e o que se poderia chamar provisoriamente de uma certa intemporalidade, são todos conceitos a serem igualmente submetidos ao princípio do nominalismo. Enfim, um outro aspecto importante, a crítica dos universais se associa ao procedimento que consiste em "descer em direção ao estudo das práticas concretas pelas quais o sujeito é constituído na imanência de um domínio do conhecimento", e não se elevar "a um sujeito constituído ao qual se pede que dê conta daquilo que pode ser todo objeto de conhecimento em geral" 21 .

20 Michel FOUCAULT, «Foucault », in Dits et écrits [Ditos e escritos] (1954-1988), op. cit., tomo IV, p. 634.

$21 \quad$ Ibid. 
Nesse ponto da análise, pode-se sintetizar, acerca dos seguintes pontos, algumas características da maneira foucaultiana de ser nominalista. Primeiramente, trata-se de um nominalismo que desessencializa aquilo sobre o que se debruça, quer seja o poder, a sexualidade, o liberalismo ou a loucura, e que assim frustra o primado, quiçá mesmo a simples consideração, das essências. Em segundo lugar, é um nominalismo que se combina a cada vez com pesquisas históricas (donde o "nominalismo histórico" que fala Balibar). Ele não é portanto, antes de tudo, usado tendo em vista estudos filosóficos no sentido estrito, de comentário, ou simplesmente em pesquisas especulativas, mas aparece como o princípio pelo viés do qual Foucault rompe o mais eficazmente com a filosofia. Em terceiro lugar, é um nominalismo que toma a via descendente, levando à análise de práticas concretas sobre um plano de imanência, ao invés de elevar o pensamento até idealidades e transcendência. Talvez seja importante acrescentar um quarto e derradeiro ponto, segundo o qual, como o diz Maurice Florence, "o sujeito e o objeto 'se formam e se transformam' um em relação ao outro e em função do outro" 22 . Esse quarto ponto é necessário para se compreender que a imanência não é um plano de essências, plano no estado mais ou menos estacionário e, ainda menos, imóvel - mas o espaço de uma mobilidade permanente que condiciona os modos de ser dos polos das relações, e, no caso presente, o sujeito e o objeto. Seria sem dúvida possível dizer que o objeto supremo ao qual se aplica o nominalismo de Foucault é o "homem", de tal modo que, se se seguir ainda o propósito de Maurice Florence, os trabalhos sobre a desrazão, a prisão e a sexualidade, para nada dizer sobre a arqueologia das ciências humanas, foram todos postos na conta de uma crítica dos universais antropológicos.

O que há disso em Marx? Um "marxismo nominalista"23 é viável? Em "Foucault e Marx. A questão do nominalismo", Balibar pretende que sim. Mas sua interpretação só é receptível com uma condição: esse nominalismo não deve ser entendido como uma

\footnotetext{
$22 \quad$ Ibid.

23 Étienne BALIBAR, < < Foucault et Marx. Ijenjeu du nominalisme » in Michel Foucault philosophe. Rencontre internationale, op. cit., p. 65.
} 
afirmação da existência primordial do que é individual, em prejuízo do que é universal, pois então não se faria senão que retomar uma das faces da medalha filosófica a qual nos referíamos acima, a do nominalismo tradicional, aposto à do realismo. Com efeito, a sexta tese sobre Feuerbach já se situa além dessa dicotomia, pois, como Balibar pôde registrar alhures, recusa uma e outra: "A que quer que o gênero, ou essência, preceda a existência dos indivíduos, e a que quer que os indivíduos sejam a realidade primeva, a partir da qual se 'faria abstração' dos universais" ${ }^{24}$. Porém, há um aspecto dessa definição do nominalismo - como um princípio que coloca na origem os "indivíduos" como "realidade" e, bem mais, como "realidade primeva" - que causa problema: ela impede que se considere a existência de um "marxismo nominalista", e isso na medida em que, segundo a sexta tese, a única realidade primeva é a das relações sociais, e não a dos indivíduos. Como vimos, essa hipótese desloca o problema da essência humana, dos indivíduos eles mesmos ${ }^{25}$ às relações sociais. Quer dizer que, se existe um nominalismo marxista, só existe em um sentido, que não privilegia o indivíduo-existente-como-realidade-primeira, a despeito do universal, mas, antes, no sentido de uma relação da qual o indivíduo e o conceito abstrato, o próprio universal, dependem e são polos. Nos colocamos diante da seguinte alternativa: ou Marx já era, bem antes de Foucault, um nominalista que dissolvia as idealidades (por exemplo, "ao analisar a exploração capitalista como um processo de consumo-reprodução da força de trabalho e como um excesso permanente sobre as formas do contrato e da troca" - nesse caso, Marx não teria feito "nada mais" do que "constituir uma analítica do poder que explicita sua natureza puramente relacional"26); ou Marx "dispensa nominalismo e essencialismo"27, caso em que não

$24 \quad$ Étienne BALIBAR, La Philosophie de Marx, op. cit., p. 69.

25 Mais rigorosamente : do « indivíduo singular » como o traduz Georges Labica, dem einzelnen lndividuum, diferentemente de Macherey que prefere "indivíduo único". Ver Pierre MACHEREY, <<Marx, thèses sur Feuerbach. Thèse six» [Marx, teses sobre Feuerbach. Tese 6], janeiro 2003. Disponível em:

<http://stl .recherche.univ-lille3 .fr/seminaires/philosophie/macherey/Macherey20022003/Macherey29012003.html $>$.

26 Étienne BALIBAR, << Foucault et Marx. L`enjeu du nominalisme 》 in Michel Foucault philosophe. Rencontre internationale, op. cit., p.74..

$27 \quad$ Étienne BALIBAR, La Philosophie de Marx, op. cit., p. 74. 
se pode considerá-lo nominalista. O enunciado dessas duas proposições leva a crer que o termo nominalismo adquire significações diferentes tanto em uma acepção quanto em outra, e que Marx só pode ser considerado nominalista em um novo sentido do termo, que afasta seu sentido clássico. Dito de outra maneira, ele não é um nominalismo do indivíduo, mas um nominalista da relação.

Essas diferentes acepções do conceito de nominalismo mostram que sua definição se modificou após sua recuperação por Foucault. Na realidade, quando Balibar evoca um "marxismo nominalista", ele o faz projetando um horizonte foucaultiano no trabalho de Marx. O nominalismo de Marx é portanto compreendido, primeiramente, no sentido foucaultiano do termo. Nessa medida, Foucault e Marx são portanto igualmente nominalistas, isso se o último não o for ainda mais. Além disso, se se deseja afirmar que Marx é nominalista, esse termo deverá significar outra coisa em relação aquilo que Marx recusava como primado do que é individual e singular. Assim, duas coisas parecem certas: de um lado, Marx e Foucault perseguem um tipo de dissolução similar que é a dos universais, em benefício das relações; e, por outro, não se pode designar esse trabalho como sendo nominalista, e portanto falar de um "marxismo nominalista", senão sob condição de um nominalismo distinto do individual, um nominalismo de tipo novo, um nominalismo foucaultiano.

\section{Como não se recair na metafísica}

Um outro aspecto da mutação do "materialismo histórico" em "nominalismo histórico" é digno de nota: trata-se da atribuição de uma função, por assim dizer negativa, ao nominalismo. E isso na medida em que impõe um limite ao pensamento. Essa função se encontra na definição do nominalismo dada por Balibar e segundo a qual ele é o "suplemento do materialismo que é necessário para se impedir uma materialidade - econômica, política ou discursiva - todo um retorno à metafí-

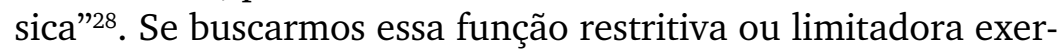
cida pelo "suplemento de materialismo" nos textos de Marx, a

$28 \quad$ Étienne BALIBAR, $<<$ Foucault et Marx. L'enjeu du nominalisme », in Michel Foucault philosophe. Rencontre internationale, op. cit., p. 75. 
encontramos não na sexta tese sobre Feuerbach, mas na segunda: "A questão de saber se é preciso dotar o pensamento humano de uma verdade objetiva não é uma questão de teoria, mas uma questão prática. É na práxis que o ser humano deve provar a verdade, quer dizer, a realidade efetiva e potente, a terrestridade, o caráter terrestre de seu pensamento. A disputa concernente à realidade ou a não realidade efetiva de um pensamento que se isola da práxis é uma questão puramente escolástica"29. Encontramos portanto esse princípio de restrição na fórmula conclusiva dessa segunda tese. Em suma, a atenção dada à práxis é o suplemento de materialismo necessário para impedir todo retorno à escolástica por parte do pensamento. Essa ideia de retorno à escolástica parece ser o equivalente do "retorno à metafísica" evocado por Étienne Balibar; assim, o princípio restritivo é tanto anti-escolástico quanto anti-metafísico.

Para que se compreenda essa regra limitadora, Marx convoca uma imagem: o "caráter terrestre" do pensamento, por oposição a um pensamento que se dirige ao além perde lugar na prática. O vocábulo alemão aqui solicitado é Diesseitigkeit, que não é ele próprio marxiano, como o recorda Pierre Macherey, mas "diretamente retomado do vocabulário de Feuerbach"30. Essa "estranha palavra quase não tem equivalente em francês. Badia a traduz por uma perífrase que a associa estreitamente ao termo Macht, e fala da necessidade de se experimentar 'a potência de seu pensamento nesse mundo e em nosso tempo'; Rubel fala da 'potência, o aqui abaixo de seu pensamento'; e Labica escreve: 'a potência, o caráter terrestre de seu pensamento"'31. Macherey traduz Diesseitigkeit por "naturalidade imanente", enquanto Pierre Dardot, quando do colóquio "Marx

$29 \quad$ Karl MARX, « Thesen über Feuerbach », in Marx-Engels Werke, vol. 3, Dietz Verlag, Berlin, 1969, p. 533. Tradução de Georges Labica (levemente modificada), in Georges LABICA, Karl Marx. Les Thèses sur Feuerbach [As teses sobre Feuerbach], PUF, Paris, 1987, p. 20.

$30 \quad$ Pierre $1 \bigvee$ LACHEREY, « Les Thèses sur Feuerbach. Les thèses 11 et III » [As teses sobre Feuerbach. As teses I e III], dezembro de 2002. Disponível em:

<http://stl.recherche.univ-lille3.fr/seminaires/philosophie/macherey/ Macherey20022003/Macherey11122002.html>.

31 Ibid. 
\& Foucault", o traduz por "o aqui abaixo terrestre", expressão que Macherrey menciona de passagem igualmente ${ }^{32}$. Essas diferentes acepções podem ser resumidas se traduzirmos Diesseitigkeit por terrestridade. E, de fato, as ligações entre a terristridade e a segunda tese foram compreendidas há muito tempo por Gramsci, que em seus "Cadernos de tradução"33 traduz o vocábulo alemão por "il carattere terrenoüil" ("o caráter terrestre"), e que em seus "Cadernos do cárcere" fala da "terrestrità assoluta del pensiero" 34 (a terrestridade absoluta do pensamento). Em "Para ler 'O Capital", Althusser retoma essa parte dos "Cadernos do cárcere", conhecida sob o nome de "O materialismo histórico e a filosofia de Benedetto Croce", e cita Gramsci: "A filosofia da práxis é o 'historicismo' absoluto, a mundanização e a 'terrestridade' absolutas do pensamento, um humanismo absoluto da história" 35 . No comentário de Althusser, se insiste sobre a dimensão crítica e polêmica do uso gramsciniano das palavras humanismo e historicismo, que visa, acrescenta, a "refutar toda interpretação metafísica da filosofia marxista" e indicar "o lugar da 'imanência', do 'aqui abaixo', que Marx já opunha [na segunda tese] como o 'diesseits' (nosso aqui abaixo) à transcendência, o para além (jenseits) das filosofias clássicas"36. Mais adiante, Althusser volta às mesmas formulações e se refere tanto ao gesto marxiano de "por fim a todo 'para além' supraterrestre" quanto à "forma distintiva essa imanência absoluta (sua 'terrestridade') (...) ${ }^{37 \prime \prime}$. A ideia althusseriana de uma terrestridade diretamente associada a uma leitura não-metafí-

32 Ver Pierre DARDOT, $<<$ De la praxis aux pratiques » [Da práxis às práticas], capítulo 13 da presente obra.

33 Antonio GRAMSCI (edição corrigida por Giuseppe Cospito et Gianni Francioni), Quaderni di traduzioni [Cadernos de tradução] (1929-1932), Istituto della Enciclopedia Italiana, Rome, 2007, p. 743.

34 Antonio GRAMSCI (edição crítica do Instituto Gramsci, sob a direção de Valentino Gerratana), «Quademo 11 (xvrn). 1932-1933 », in Quaderni del carcere, vol. 2, Quaderni 6-11, Einaudi, Turin, 1977, p. 1437. Ver Antonio GRAMSCI, Cahiers de prison [Cadernos do cárcere], Gallimard, Paris, 1996.

35 Antonio GRAMSCI, Il Materialismo Storico et la Filosofia di B. Croce, Einaudi, Turin, p. 159, citado por Louis Althusser in Louis ALTHUSSER et al., Lire Le Capital, PUF, Paris, 1996, p. 321.

36

Ibid.

37

Ibid., p. 326. 
sica do marxismo caminha no sentido de minha interpretação do princípio anti-escolástico como princípio anti-metafísico. Além disso, um número expressivo de outros autores também sublinha a conexão entre a segunda tese e o vocabulário retido pelos "Cadernos do cárcere". É o caso de Peter D. Thomas, em "The Gramscian Moment: Philosophy, Hegemony and Marxism » [O momento gramsciano: filosofia, hegemonia e marxismo], obra na qual a tese em questão surge como um meio de levar a verdade "à terra" ("down to Earth") ${ }^{38}$. Mais longe no mesmo livro, o autor encontra na "noção de uma Diesseitigkeit anti-metafísica do pensamento" um "ponto de vista privilegiado para estabelecer um diálogo com a referência corrente aos [...] diferentes conceitos de imanência no pensamento radical contemporâneo"39. A tradução que propomos de Diesseitigkeit por terrestridade apoia-se portanto em todas essas interpretações e marca o contraste entre os dois lados da mesma linha: o aqui abaixo (das Diesseits) ou abaixo (diesseits), em oposição entre lá acima ou para além. O princípio negativo recomenda à pesquisa permanecer desse lado da linha e de não a atravessar.

Sobre Foucault, segundo o texto "Foucault e Marx. A questão do nominalismo", ele é também um pensador do suplemento de materialismo. Em particular em razão da maneira pela qual aborda a "materialidade [...] dos dispositivos e das práticas de poder, enquanto se exercem nos corpos" ${ }^{40}$. Em suma, o nominalismo da relação que liga Marx e Foucault não somente dissipa as idealidades, mas é também um método que confina o pensamento ao que é terrestre, que sela seu

38 Peter D. THOMAS, The Gramscian Moment : Philosophy, Hegemony and Marxism, Brill, Leide, 2009, p. 308.

$39 \quad$ Ibid., p. 449. Outros autores caminham no mesmo sentido: Cyril SMITH, Karl Marx and the Future of the Human [Karl Marx e o futuro do humano], Lexington Books, Lanham, 2005, p. 199 ; Richard KILMINSTER, Praxis and Method. A Sociological Dialogue with Lukács, Gramsci and the Early Frankfurt School [Práxis e método : um diálogo sociológico com Lukács, Gramsci e a primeira Escola de Frankfurt], Routledge, Londres/New York, 2014, p. 18 ; ver a referência feita por Étienne Balibar no quadro de uma análise das teses, em "um pensamento que se quer efetivo, terrestre ou 'mundano"', in Étienne BALIBAR, La Philosophie de Marx, op. cit., p. 54.

40 Étienne BALIBAR, « Foucault et Marx. L'enjeu du nominalisme » in Michel Foucault philosophe. Rencontre internationale, op. cit., p. 73. 
pertencimento à imanência. É o que é explicado na entrado do dicionário assinada por Maurice Florence, posto que ali se defende o princípio metodológico segundo o qual sempre é preciso provar e analisar "tudo aquilo que nos é proposto em nosso saber, como validade universal, quanto à natureza humana ou às categorias que se pode aplicar ao sujeito". Da mesma maneira, a associação do requisito da prova e da análise a uma necessidade de se "redescer ao estudo das práticas concretas pelas quais o sujeito é constituído na imanência de um domínio do conhecimento". Esse movimento de descida nos parece totalmente compatível como o de redescida à terra para aí se fixar - gesto de permanecer fiel à terristridade do pensamento.

Em conclusão, para além de suas diferenças, Marx e Foucault possuem, em suas relações problemáticas com a filosofia, um ponto comum, revelador de outras importantes proximidade, das quais três merecem ser realçadas: primo, sua paixão para desfazer as essências em prol das relações; secundo, o recurso a um método que se poderia chamar (e que Foucault de fato chamou) nominalista, as que é um nominalismo da relação e não do indivíduo; tertio, a necessidade de permanecer na imanência das práticas e da história para não se recair na escolástica ou na metafísica. A aparição do motivo antropológico no quadro dessa análise não é um acaso, e é espantoso constatar que o nominalismo de Foucault ataque os universais antropológicos, como o que se poderia imputar a Marx visa diretamente a essência humana. Resta agora pesquisar como essas duas variantes de Pan-antihumanismo teórico podem nos ser úteis hoje, para refletirmos acerca de um discurso sobre o humano, uma vez admitido que o "homem" não passa de um nome. 